\title{
Radical cascades using enantioenriched 7-azabenzonorbornenes and their applications in synthesis
}

\author{
David M. Hodgson* and Leonard H. Winning
}

\section{Full Research Paper}

\section{Address:}

Department of Chemistry, Chemistry Research Laboratory, University of Oxford, Mansfield Road, Oxford, OX1 3TA, UK; Fax: +44(1865) 285002

Email:

David M. Hodgson* - david.hodgson@chem.ox.ac.uk

* Corresponding author

Keywords:

asymmetric synthesis; deoxygenation; radicals; rearrangements; tandem reactions

\author{
Beilstein Journal of Organic Chemistry 2008, 4, No. 38 \\ doi:10.3762/bjoc. 4.38 \\ Received: 09 September 2008 \\ Accepted: 14 October 2008 \\ Published: 24 October 2008 \\ (C) 2008 Hodgson and Winning; licensee Beilstein-Institut. \\ License and terms: see end of document.
}

\begin{abstract}
Tandem deoxygenation-neophyl-type radical rearrangement-electrophile trapping using xanthates from 7-azabenzonorbornadienes gives 3-exo-substituted 2-aza-5,6-benzonorbornenes, which in some cases undergo isomerisation to (aminomethyl)indenes. The starting xanthates are accessible in good yields and high enantiomeric ratios via asymmetric hydroboration of (aryne/pyrrolederived) 7-azabenzonorbornadienes. Oxidation (using $\mathrm{RuO}_{4}$ ) and Birch reduction of the 2-aza-5,6-benzonorbornenes provide access to substituted pyrrolidines and tetrahydroindenes, respectively.
\end{abstract}

\section{Introduction}

Carbon-centred radicals have been shown to be useful intermediates in organic chemistry with widespread applications in synthesis [1-6]. Significant advantages can be gained by the use of radical intermediates: for example, despite their highly reactive nature, radical intermediates can be generated under mild conditions without the need for strongly acidic or basic environments [7]. Furthermore, an understanding of radical chain reactions has enabled radical-based methods to be applied to the synthesis of complex targets [8,9], and routes using radical intermediates can readily be considered during retrosynthetic planning [10].
The cyclopropylmethyl radical (1) is known to ring-open to homoallyl radical (2) with a rate of $1.2 \times 10^{8} \mathrm{~s}^{-1}$ at $37{ }^{\circ} \mathrm{C}$ (Scheme 1) [11].

Substituted cyclopropylmethyl-homoallylic radical systems are found embedded in a range of more complex substrates, such as those based upon the bicyclo[2.2.1] heptenyl (norbornenyl) framework. In these latter systems, nortricyclyl radical 3 can undergo reversible ring-opening to norbornenyl radical 4; treatment of nortricyclyl or norbornenyl bromide with $\mathrm{Bu}_{3} \mathrm{SnH}$ and AIBN is known to lead to the same (approximately equal) 


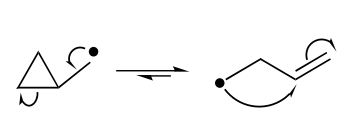

1

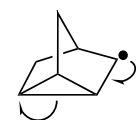

3

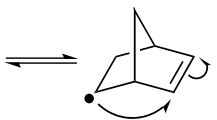

4
Scheme 1: Cyclopropylmethyl-homoallyl and nortricyclyl-norbornenyl radical systems.

mixture of nortricyclane and norbornene $[12,13]$. The final product distribution in these systems is found to be heavily dependent on the reactant concentrations as well as on the structure of the substrate. In synthetic applications it is therefore important to be able to bias the rearrangement in favour of the desired product, which is most conveniently achieved by the incorporation of one or more structural directing effect(s). Research in our laboratory has focussed on using the potential dative stabilising effect of an $\alpha$-nitrogen in the product-producing radical to direct homoallylic radical rearrangements for use in azacycle synthesis [14].

The utility of nitrogen-directed radical rearrangements in the 7-azanorbornene system has been reported previously in relation to the synthesis of a variety of biologically-relevant targets, including epibatidine analogues $[15,16]$, kainic acid $[17,18]$ and ibogamine [19]. In these studies, the radical step has mainly been carried out in the presence of a relatively fast radical reductant (e.g. $\mathrm{Bu}_{3} \mathrm{SnH}$ ). More recently, investigations have centred on the use of (TMS) ${ }_{3} \mathrm{SiH}$ as a slower hydrogen atom donor, with a view to affecting tandem radical generation-rearrangement-electrophile trapping for the rapid enhancement of molecular complexity. Furthermore, in the structurally similar system created by the formal fusion of the norbornenyl skeleton with an aromatic ring, the 'nortricyclyl' radical is delocalised in the originally aromatic $\pi$-system. Ringopening of this 'nortricyclyl' radical species can lead to an overall 1,2-aryl (neophyl) migration [20]. We have previously communicated our initial findings in the application of tandem radical cascades toward the 2-aza-5,6-benzonorbornenyl system [21]. We now present our wider investigations of this system and its synthetic utility.

\section{Results and Discussion}

Chatgilialoglu and co-workers have previously shown that (TMS) ${ }_{3} \mathrm{SiH}$-mediated xanthate deoxygenations can be performed in tandem with electrophile trapping [22,23]. We were encouraged that the best yields of deoxygenated, trapped product relative to directly reduced product were achieved under conditions [refluxing toluene, thermal initiation by AIBN] similar to those we had previously reported for the tandem deoxygenation-rearrangement-reduction of 7-azabenzonorbornenyl xanthates (e.g. 5 to $\mathbf{8}$, Scheme 2), although the work in our laboratory had employed a syringe pump in order to achieve a slow rate of addition of the radical initiator and reductant $[21,24]$. Pleasingly, combining these procedures, i.e. performing a slow addition of $\mathrm{AIBN},(\mathrm{TMS})_{3} \mathrm{SiH}$ ( 1.5 equiv) and acrylonitrile ( 1.5 equiv) to a $0.03 \mathrm{M}$ solution of xanthate 5 $[24,25]$ in refluxing toluene, resulted in the formation of rearranged-trapped azacycle $\mathbf{9}$, in $77 \%$ yield (Scheme 2 ), and exclusively as the exo-isomer (for details see Supporting Information File 1).

In contrast to Chatgilialoglu's work, products from reduction of radicals 6 or 7 were not observed, nor was the product of electrophile trapping by the unrearranged radical $\mathbf{6}$ detected. By-products isolated from the reaction all showed large $\mathrm{Me}-\mathrm{Si}$ signals in their ${ }^{1} \mathrm{H}$ NMR spectra, suggesting that the (TMS) ${ }_{3} \mathrm{Si}$ radical had added to the system; however the structures of these compounds could not be determined. The selectivity that is observed for the product azacycle 9 can be rationalised in terms of the higher energy SOMO and therefore higher nucleophili-

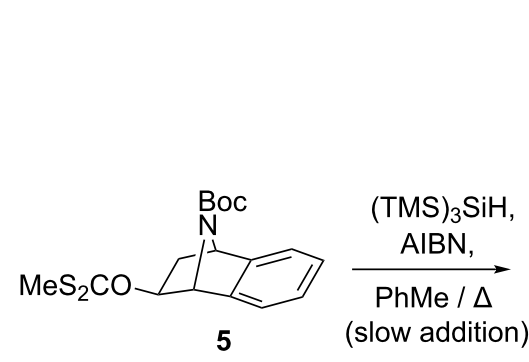

(b) $+\mathrm{NC}_{\downarrow}$
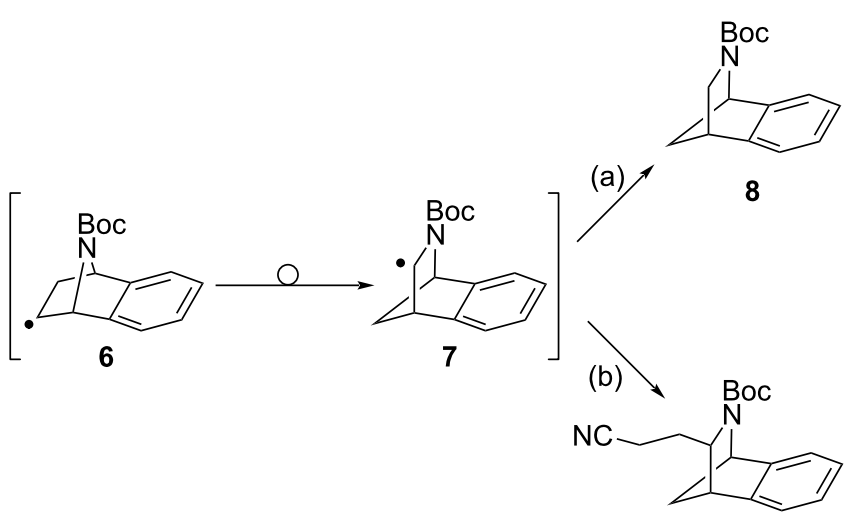

9 
city of the rearranged radical 7 (Figure 1), compared to the unrearranged radical 6 . The more nucleophilic rearranged radical therefore reacts selectively with the electrophile rather than with the silane, resulting in electrophile trapping rather than reduction.

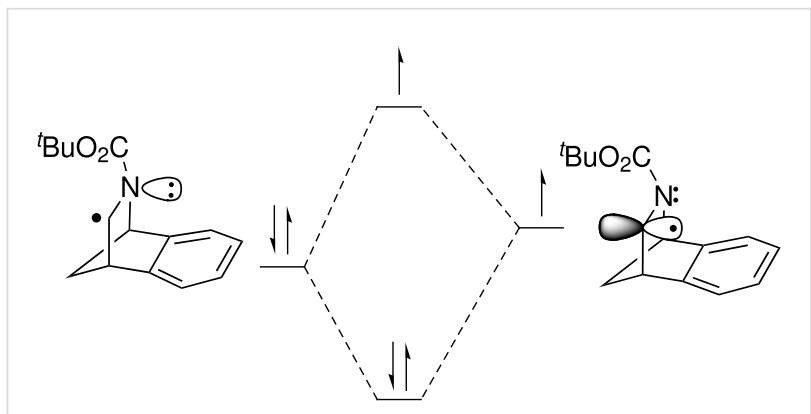

Figure 1: Radical SOMO/a-nitrogen lone-pair interaction in the rearranged radical 7 .

Encouraged by the above initial result, a number of other electrophiles were considered for the tandem deoxygenation-rearrangement-trapping reaction (Figure 2). Acrylate esters proved effective electrophiles: methyl acrylate and tertbutyl acrylate gave rearranged trapped products $\mathbf{1 0}$ and $\mathbf{1 1}$ in yields of $56 \%$ and $61 \%$, respectively. $\alpha, \beta$-Unsaturated aldehydes were also tolerated: crotonaldehyde gave a separable mixture $(\sim 2: 1)$ of diastereomeric aldehydes $\mathbf{1 2}$ in a combined yield of 55\%. Deoxygenation-rearrangement-electrophile trapping with acrolein was also considered, however the practical difficulties of using this reagent (prone to polymerisation in the absence of a radical inhibitor) precluded its application. Using 3-methyl-2-butenal led to only rearranged-reduced product $\mathbf{8}$ (79\%). In many cases, radical reactions are considered to proceed through early transition states and, as such, steric effects are not usually significant [7]. Therefore, the lack of reactivity with 3-methyl-2-butenal could be due to the positive inductive effect of the terminal methyl groups rendering the $\beta$-position of the aldehyde less electrophilic.

In an attempt to access a simple trapped aldehyde indirectly, acrolein diethyl acetal was tested as a potential electrophile, however only the rearranged-reduced product 8 was obtained (81\%); 1-heptene similarly gave only rearranged-reduced azacycle 8 , in $81 \%$ yield. These latter results were indicative of a generally-observed trend that alkenes bearing less strongly electron-withdrawing substituents were less effective electrophiles in this reaction. Phenyl vinyl sulfone gave trapped rearranged azacycle $\mathbf{1 3}$ in $43 \%$ yield, with rearranged-reduced azacycle $\mathbf{8}$ also isolated in 38\% yield, suggesting that the rate of electrophile trapping with the sulfone corresponds approximately to the rate of hydrogen atom transfer from (TMS) ${ }_{3} \mathrm{SiH}$. Attempted reaction with methyl vinyl ketone, $N, N$-dimethylacrylamide and methyl propiolate gave rearranged-reduced azacycle $\mathbf{8}$ in modest yields, as well as small quantities of hydrosilylated electrophile (for details see Supporting Information File 1) [26].

Having probed the generality of the reaction, attempts were made to optimise the yields of the electrophile trapping. These studies were performed with phenyl vinyl sulfone, since this had undergone partial electrophile trapping and partial rearrangement-reduction under the standard conditions. It was considered that a greater excess of the electrophile might bias the product distribution in favour of electrophile trapping; however, it was found that increasing the concentration of the olefin resulted in a decrease in the yield of the desired rearranged-trapped azacycle 13. This result, in conjunction with the silylated by-products recovered from these reactions, supports the hypothesis that (reversible) hydrosilylation of the electrophile may be a significant competing pathway in these reactions.

With a viable method for the deoxygenation-rearrangementtrapping of 2-azabenzonorbornenyl xanthates established, we next sought to achieve an asymmetric access to such systems by asymmetric hydroboration. Previous test reactions had indicated that efficient metal-catalysed asymmetric hydroboration [27] was difficult to achieve in this system [28] and therefore stoichiometric hydroboration was examined. The timely work of Laschat and co-workers in an analogous tropinone system [29] suggested the application of diisopinocampheylborane $\left(\mathrm{Ipc}_{2} \mathrm{BH}\right)[30,31]$, which with cycloadduct 14 at $0{ }^{\circ} \mathrm{C}$ gave

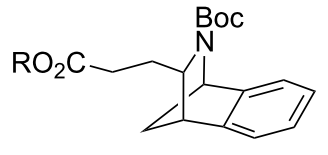

$10(\mathrm{R}=\mathrm{Me}) 56 \%$ $11\left(\mathrm{R}={ }^{t} \mathrm{Bu}\right) 61 \%$

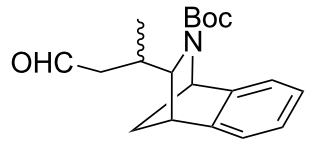

$1255 \%$

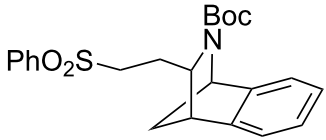

$1343 \%$

Figure 2: Other products obtained from xanthate 5 by tandem deoxygenation-rearrangement-electrophile trapping 
alcohol 15 in $84 \%$ yield $\left(68 \%\right.$ at $-10{ }^{\circ} \mathrm{C}$, Scheme 3$)$. HPLC analysis revealed that alcohol $\mathbf{1 5}$ formed in excellent enantiomeric ratio (er) [32] (97:3) at both temperatures.

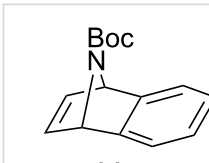

14
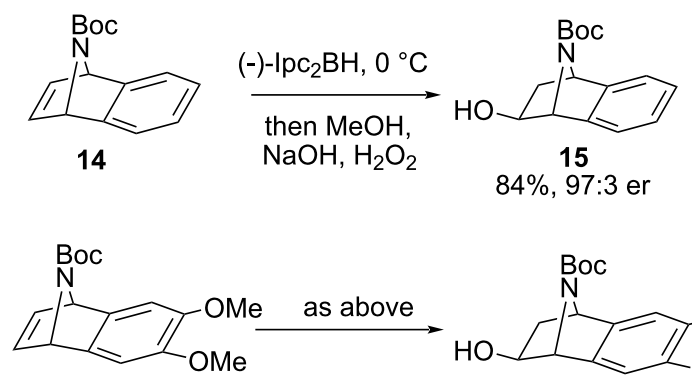

16
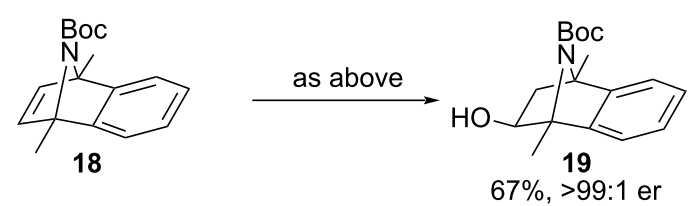

$67 \%$, >99:1 er

Scheme 3: Asymmetric hydroboration-oxidation of alkenes 14, 16 and 18.

Encouraged by the high hydroboration selectivity, two related cycloadducts, 16 [24] and 18 [28] with differing electronic and structural properties were examined (Scheme 3 ) which led to the corresponding alcohols $\mathbf{1 7}$ and $\mathbf{1 9}$ in similar ers.

With highly enantioenriched alcohols $\mathbf{1 7}$ and $\mathbf{1 9}$ in hand, the possibility of extending the tandem deoxygenation-rearrange- ment-electrophile trapping to these substrates was examined. Simple deoxygenation-rearrangement-reduction of the methyl xanthate derivatives $\mathbf{2 0}$ and $\mathbf{2 3}$ were performed as initial test reactions (Scheme 4). However, product profiles of these reactions were found to be inconsistent: the expected rearranged bridged azacycles 21 and $\mathbf{2 4}$ could be observed by ${ }^{1} \mathrm{H}$ NMR, provided that the spectra were recorded immediately after isolation. But in most experiments some degree of isomerisation to (aminomethyl)indenes $\mathbf{2 2}$ and $\mathbf{2 5}$ respectively were observed, as indicated by the appearance of vinylic $\mathrm{CH}$ resonances in the ${ }^{1} \mathrm{H}$ NMR spectra $(\delta 6.8-6.0)$. This isomerisation is presumably the result of trace acid catalysis, with the process likely proceeding via protonation of the nitrogen atom, followed by ring opening to a stabilised benzylic cation. ${ }^{1} \mathrm{H}$ NMR analysis also revealed that the resulting (aminomethyl)indenes 22 and $\mathbf{2 5}$ degraded with time.

The tandem deoxygenation-rearrangement-electrophile trapping reaction was attempted for xanthates $\mathbf{2 0}$ and $\mathbf{2 3}$ using acrylonitrile and, whilst the expected rearrangement-trapping occurred (as judged by diagnostic features in the crude ${ }^{1} \mathrm{H}$ NMR spectra, for details see Supporting Information File 1), isomerisation of the initial adducts to the corresponding chromatographically sensitive indenes commenced rapidly; this may account for the modest isolated yields of the trapped azacycles (Scheme 5). Further electrophile trapping experiments were undertaken with dimethyl xanthate 23: methyl acrylate and phenyl vinyl sulfone gave the corresponding indenes $\mathbf{3 0}$ and $\mathbf{3 1}$, which could both be isolated, albeit in modest yields.

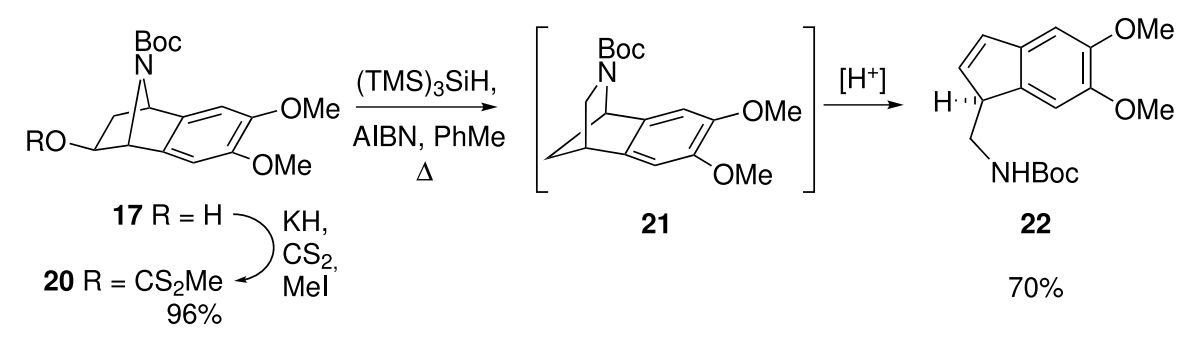

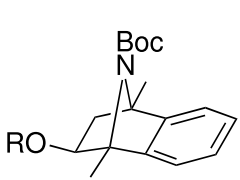

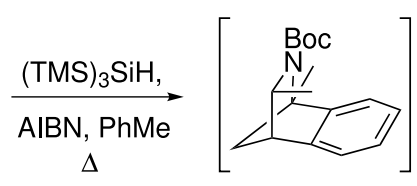<smiles>C[In]</smiles><smiles>CC1=CC(C(C)NC(=O)OCc2ccccc2)c2ccccc21</smiles>

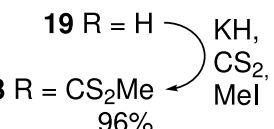

24

$60 \%$ 


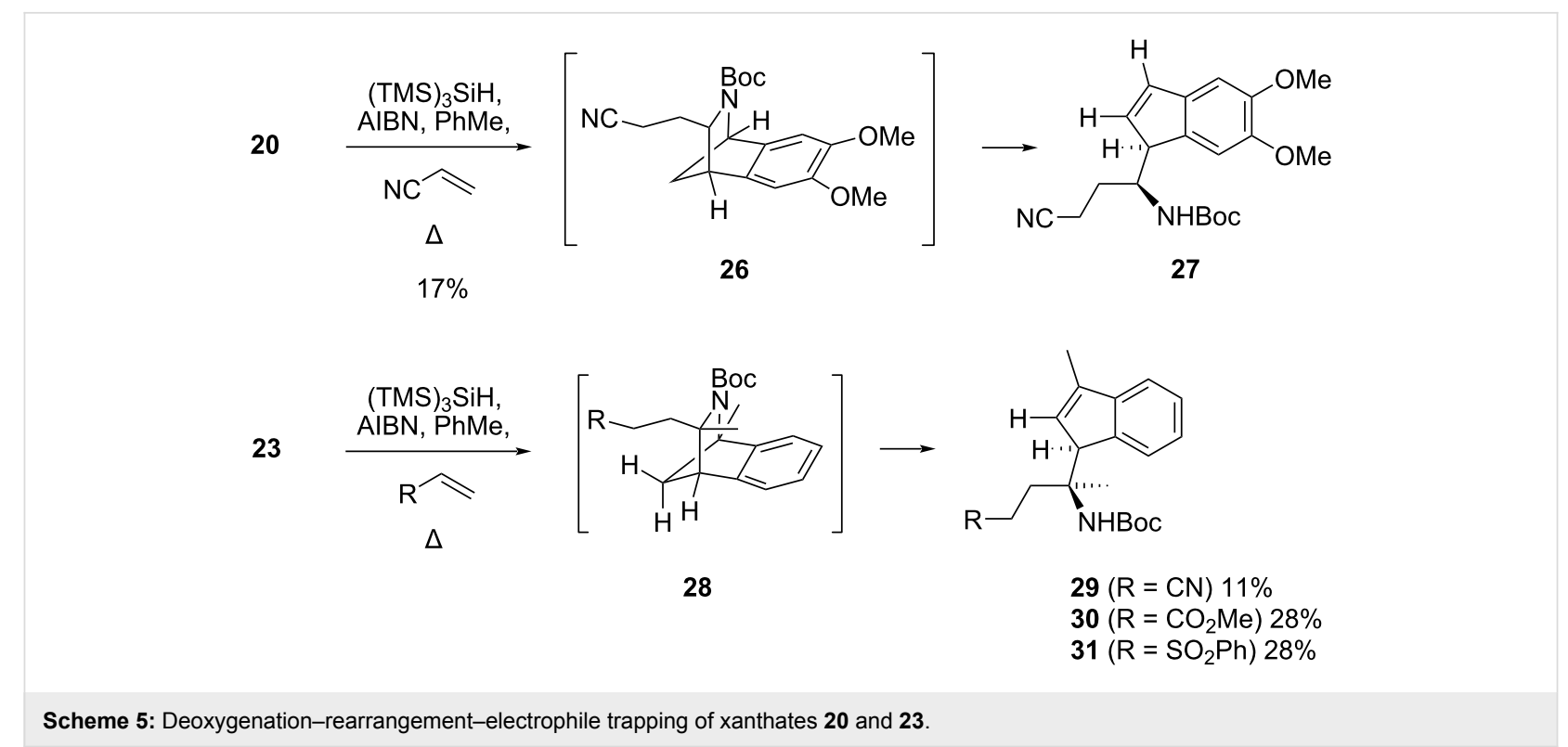

Having established a stereoselective route to 3-exo-substituted 2-azabenzonorbornenes, further synthetic transformations of these adducts were addressed. Firstly, we considered that the 2-azabenzonorbornene framework could be a masked pyrrolidine: cleavage of the aromatic ring would reveal a stereodefined 2,4-disubstituted pyrrolidine (Scheme 6). This transformation was of interest because the pyrrolidine ring is a common nitrogen-containing motif in natural products and pharmaceutically relevant molecules [33].

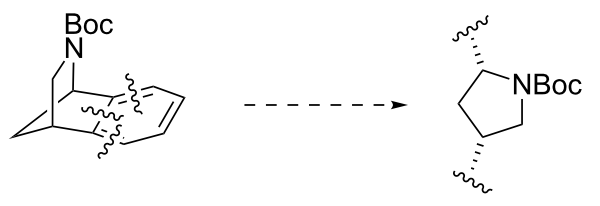

Scheme 6: 2-Azabenzonorbornene as a masked pyrrolidine.

Ruthenium tetraoxide was first examined as a reagent for the oxidative cleavage of the aromatic ring, since treatment of alkyl-substituted arenes is known to result in complete oxidation to the corresponding alkyl carboxylic acids [34,35]. In the event, application of standard literature oxidation conditions $\left(\mathrm{RuCl}_{3} \cdot \mathrm{H}_{2} \mathrm{O}, \mathrm{H}_{5} \mathrm{IO}_{6}\right.$ in $\left.\mathrm{CCl}_{4} / \mathrm{H}_{2} \mathrm{O} / \mathrm{MeCN}\right)$ with rearranged-reduced azacycle 8 followed by attempted esterification $\left(\mathrm{Me}_{3} \mathrm{SiCHN}_{2}\right)$ to aid isolation led only to a Boc-protected (aminomethyl)indanone (+)-34 (38\%, Scheme 7). Ring-opening may have been catalysed by the periodic acid followed by trapping of the resulting benzylic cation $\mathbf{3 2}$ by water to give alcohol 33 and subsequent oxidation by $\mathrm{RuO}_{4}$.
Switching to sodium periodate as the stoichiometric oxidant and esterification using $\mathrm{CH}_{2} \mathrm{~N}_{2}$ gave diester 35 (49\%, 37\% using $\mathrm{Me}_{3} \mathrm{SiCHN}_{2}$ ). Attempts to improve the procedure further by the use of alternative solvents proved unsatisfactory. Azacycle $(+)-$ 10, the product of deoxygenation-rearrangement-trapping with methyl acrylate (Figure 2), was subject to the same conditions as azacycle (+)-8 and was found to give trisubstituted pyrrolidine $\mathbf{3 6}$, in $23 \%$ yield (Scheme 8 ).

Although the yields for these reactions were modest, access to pyrrolidine (+)-35 allowed the absolute sense of asymmetric induction in the hydroboration-oxidation with $(-)-\mathrm{Ipc}_{2} \mathrm{BH}$ to be determined by chemical correlation. Pyrrolidine 35 was independently prepared from $(1 R)-(-)$-2-azabicyclo[2.2.1]hept-5-en3-one (Vince's lactam [36], 37) via reduction with $\mathrm{LiAlH}_{4}$, Boc-protection and oxidative cleavage [37] (Scheme 9). The pyrrolidines prepared from rearranged azacycle $(+)-8$ and lactam 37 were both dextrorotatory, confirming the provisional assignment of configuration that had been made by analogy with Laschat's work [29].

Since attempts to effect $\mathrm{RuO}_{4}$-mediated oxidative cleavage of 2-azabenzonorbornene $\mathbf{8}$ employing periodic acid as the stoichiometric co-oxidant resulted in the formation of (aminomethyl)indanone 34, the possibility of performing this reaction with a milder oxidant was investigated. If the putative mechanism for the reaction was correct (Scheme 7), it seemed likely that a similarly strong acid would be needed. After some test reactions, the use of a 1:1 mixture of aqueous $\mathrm{HCl}$ and THF was found to consume azacycle ( + )-8 to give (aminomethyl)indanol 33 (56\% yield) and subsequent oxidation using NMO/TPAP [38] gave (aminomethyl)indanone (+)-34 (80\%, Scheme 10). 


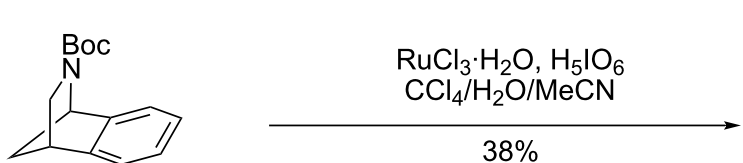

$(+)-8$

$\left[\mathrm{H}^{+}\right]$
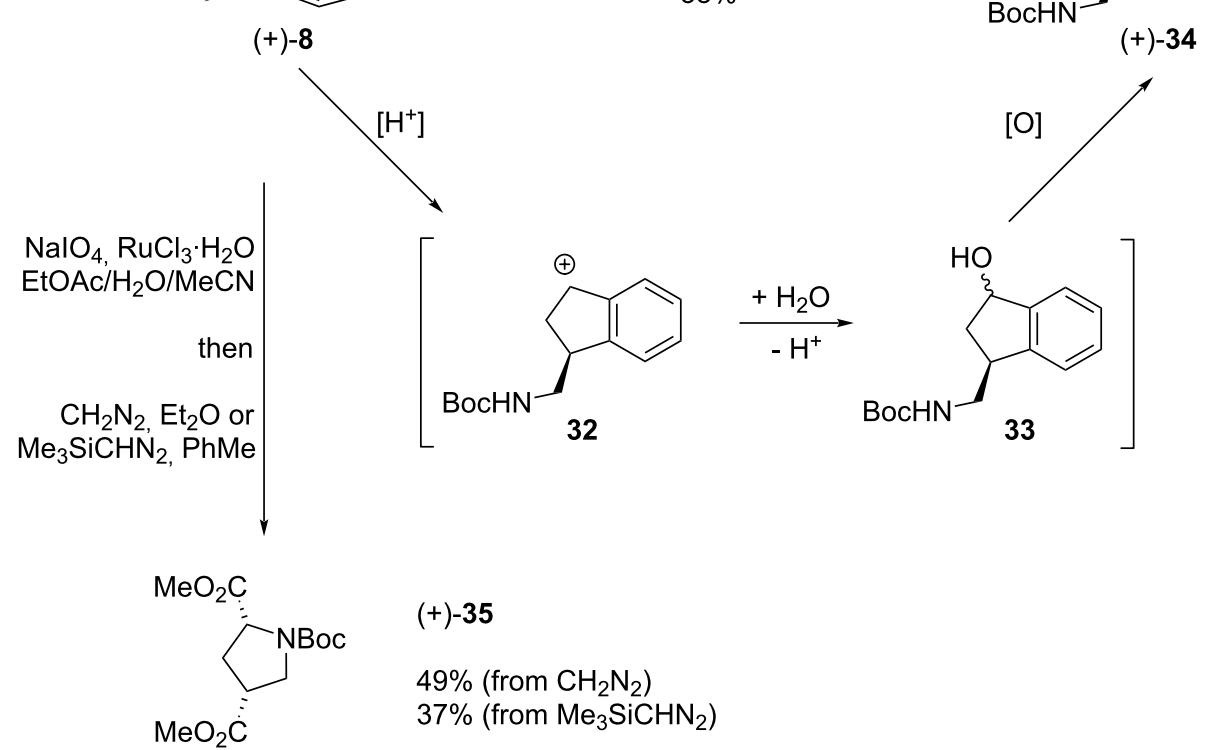

$(+)-35$

$49 \%$ (from $\mathrm{CH}_{2} \mathrm{~N}_{2}$ )

$37 \%\left(\right.$ from $\mathrm{Me}_{3} \mathrm{SiCHN}_{2}$ )

Scheme 7: Ring-opening-hydration-oxidation of azacycle 8.

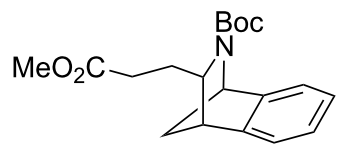

$(+)-10$

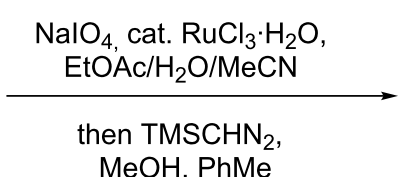

$\mathrm{MeOH}, \mathrm{PhMe}$

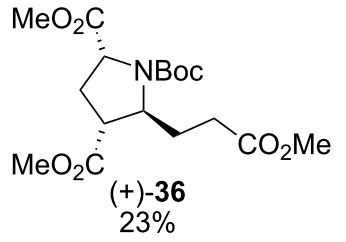

Scheme 8: Preparation of trisubstituted pyrrolidine (+)-36.

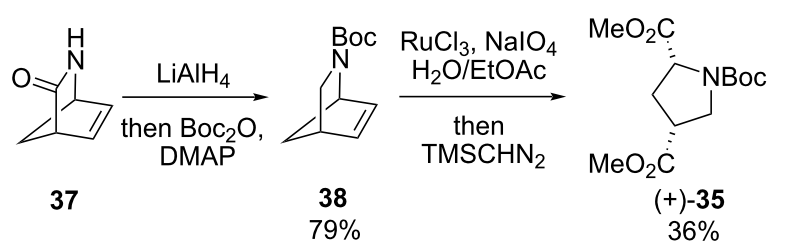

Scheme 9: Preparation of pyrrolidine diester (+)-35 from Vince's lactam 37.

Having examined oxidative cleavage of the aromatic portion of the 2-azabenzonorbornenyl framework and acid-catalysed rearrangement, reduction also presented an attractive means of modifying the carbon skeleton. Reduction of azacycle $(+)-\mathbf{8}$ under standard Birch conditions [39], gave diene $(+)-39(53 \%$ yield, Scheme 11) and indane $40(32 \%)$. Birch reduction of substituted 2-azabenzonorbornene $(+)-\mathbf{1 0}$ gave diene $(+)-\mathbf{4 1}$ $(56 \%)$, where concomitant reduction of the ester functionality had occurred.

\section{Conclusion}

Electrophile trapping in stannane-mediated dehalogenations and silane-mediated xanthate deoxygenations have previously been reported $[1,14]$. The present work provides examples in which the intermediate radical undergoes rearrangement prior to electrophile trapping, thereby providing a new route to substituted 2-aza-5,6-benzonorbornenes. These adducts have been shown to lead on to pharmaceutically significant [40] (aminomethyl)indenes, and to substituted pyrrolidines and tetrahydroindenes following oxidative and reductive transformations, respectively. 

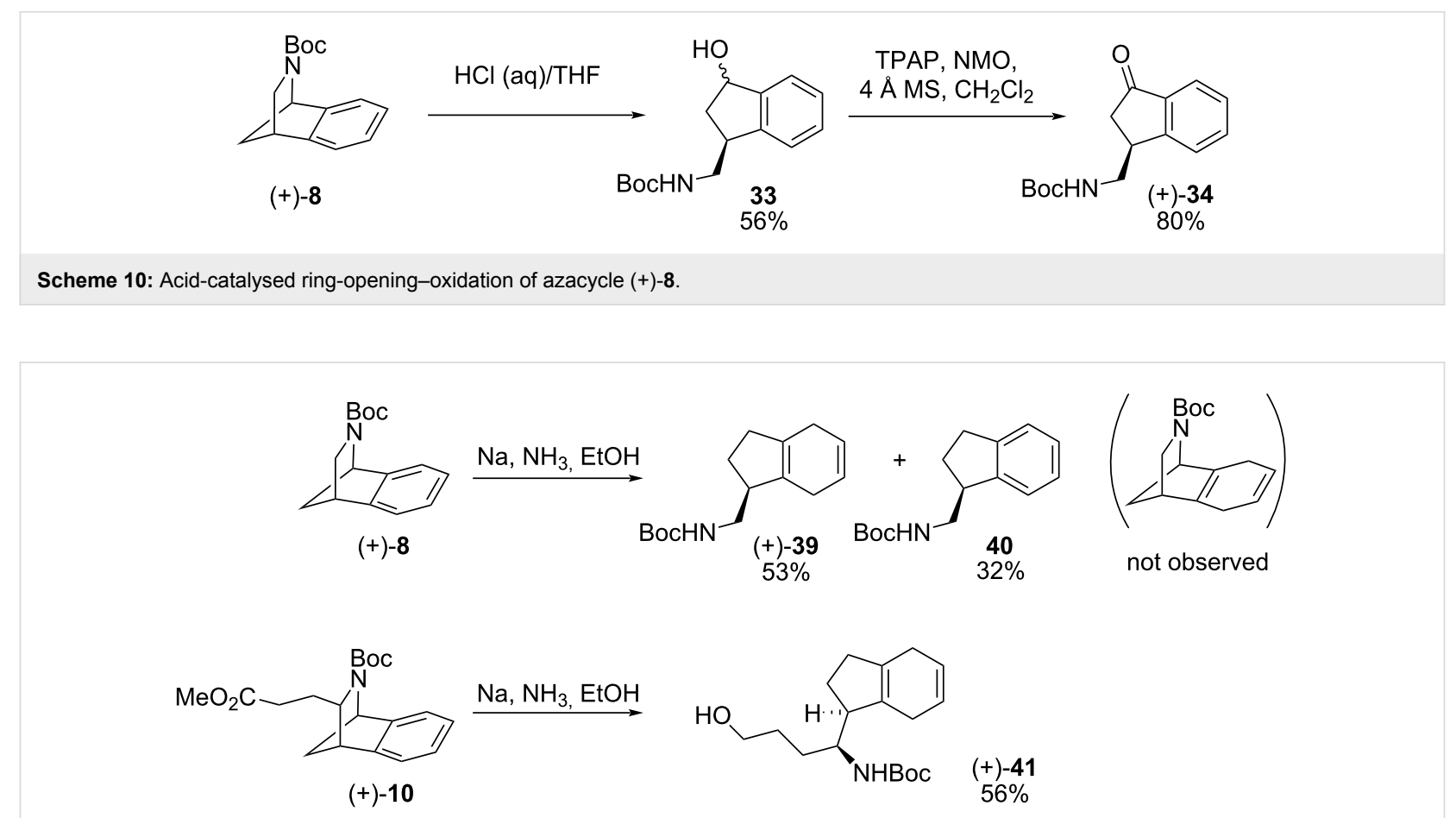

Scheme 11: Birch reduction of (+)-8 and 10.

\section{Supporting Information}

\section{Supporting Information File 1}

Full preparative details of all compounds prepared are reported, together with their spectroscopic data. [http://www.beilstein-journals.org/bjoc/content/ supplementary/1860-5397-4-38-S1.doc]

\section{Acknowledgments}

We thank the EPSRC for funding and Eli Lilly for a scholarship. We also thank Dr. B. Odell (Oxford) for assistance with structure determination using NMR and the EPSRC National Mass Spectrometry Service Centre for mass spectra.

\section{References}

1. Giese, B. Radicals in Organic Synthesis: Formation of Carbon-Carbon Bonds; Pergamon Press: Oxford, 1986.

2. Motherwell, W. B.; Crich, D. Free Radical Chain Reactions in Organic Synthesis; Academic Press: London, 1992.

3. Renaud, P.; Sibi, M. P. Radicals in Organic Synthesis; Wiley-VCH: Weinheim, 2001.

4. Togo, H. Advanced Free Radical Reactions for Organic Synthesis; Elsevier: Oxford, 2004.

5. Gansäuer, A., Ed. Radicals in Synthesis I; Topics in Current Chemistry, Vol. 263; Springer: Berlin/Heidelberg, 2006. doi:10.1007/11420187

6. Gansäuer, A., Ed. Radicals in Synthesis II; Topics in Current Chemistry, Vol. 264; Springer: Berlin/Heidelberg, 2006. doi:10.1007/11615064
7. Jasperse, C. P.; Curran, D. P.; Fevig, T. L. Chem. Rev. 1991, 91, 1237-1286. doi:10.1021/cr00006a006

8. Curran, D. P. Synthesis 1988, 417-439. doi:10.1055/s-1988-27600

9. Curran, D. P. Synthesis 1988, 489-513. doi:10.1055/s-1988-27620

10. Curran, D. P. Synlett 1991, 63-72. doi:10.1055/s-1991-20631

11. Bowry, V.; Lusztyk, J.; Ingold, K. U. Pure Appl. Chem. 1990, 62, 213-216. doi:10.1351/pac199062020213

12. Cristol, S. J.; Brindell, G. D.; Reeder, J. A. J. Am. Chem. Soc. 1958, 80, 635-640. doi:10.1021/ja01536a034

13. Cristol, S. J.; Davies, D. I. J. Org. Chem. 1964, 29, 1282-1284. doi:10.1021/jo01029a002

14. Hodgson, D. M.; Winning, L. H. Org. Biomol. Chem. 2007, 5, 3071-3082. doi:10.1039/b707566a

15. Hodgson, D. M.; Maxwell, C. R.; Matthews, I. R. Synlett 1998, 1349-1350. doi:10.1055/s-1998-1963

16. Hodgson, D. M.; Maxwell, C. R.; Wisedale, R.; Matthews, I. R.; Carpenter, K. J.; Dickenson, A. H.; Wonnacott, S. J. Chem. Soc., Perkin Trans. 1 2001, 3150-3158. doi:10.1039/b107414h

17. Hodgson, D. M.; Hachisu, S.; Andrews, M. D. Org. Lett. 2005, 7, 815-817. doi:10.1021/ol047557u

18. Hodgson, D. M.; Hachisu, S.; Andrews, M. D. J. Org. Chem. 2005, 70, 8866-8876. doi:10.1021/jo0513865

19. Hodgson, D. M.; Galano, J.-M. Org. Lett. 2005, 7, 2221-2224. doi:10.1021/ol050627s

20. Studer, A.; Bossart, M. Tetrahedron 2001, 57, 9649-9667. doi:10.1016/S0040-4020(01)00990-5

21. Hodgson, D. M.; Winning, L. H. Synlett 2006, 2476-2479. doi:10.1055/s-2006-950418

22. Ballestri, M.; Chatgilialoglu, C.; Clark, K. B.; Griller, D.; Giese, B.; Kopping, B. J. Org. Chem. 1991, 56, 678-683. doi:10.1021/jo00002a035 
23. Chatgilialoglu, C. Organosilanes in Radical Chemistry; Wiley: Chichester, 2004.

24. Hodgson, D. M.; Bebbington, M. W. P.; Willis, P. Org. Biomol. Chem. 2003, 1, 3787-3798. doi:10.1039/b306717n

25. Hodgson, D. M.; Bebbington, M. W. P.; Willis, P. Org. Lett. 2002, 4, 4353-4356. doi:10.1021/ol027039o

26. Kopping, B.; Chatgilialoglu, C.; Zehnder, M.; Giese, B. J. Org. Chem. 1992, 57, 3994-4000. doi:10.1021/jo00040a048

27. Beletskaya, I.; Pelter, A. Tetrahedron 1997, 53, 4957-5026. doi:10.1016/S0040-4020(97)00001-X

28. Bebbington, M. W. P. Nitrogen-directed free radical rearrangements. D.Phil. Thesis, University of Oxford, U.K., 2002.

29. Cramer, N.; Laschat, S.; Baro, A.; Frey, W. Synlett 2003, 2175-2177. doi:10.1055/s-2003-42080

30. Brown, H. C.; Ramachandran, P. V. J. Organomet. Chem. 1995, 500, 1-19. doi:10.1016/0022-328X(95)00509-O

31. Brown, H. C.; Singram, B. J. Org. Chem. 1984, 49, 945-947. doi:10.1021/jo00179a041

32. Gawley, R. E. J. Org. Chem. 2006, 71, 2411-2416. doi:10.1021/j0052554w

33. O'Hagan, D. Nat. Prod. Rep. 2000, 17, 435-446. doi:10.1039/a707613d

34. Mander, L. N.; Williams, C. M. Tetrahedron 2003, 59, 1105-1136. doi:10.1016/S0040-4020(02)01492-8

35. Piatak, D. M.; Herbst, G.; Wicha, J.; Caspi, E. J. Org. Chem. 1969, 34, 116-120. doi:10.1021/jo00838a028

36. Daluge, S.; Vince, R. J. Org. Chem. 1978, 43, 2311-2320. doi:10.1021/jo00406a002

37. Arakawa, Y.; Yasuda, M.; Ohnishi, M.; Yoshifuji, S. Chem. Pharm. Bull. 1997, 45, 255-259.

38. Ley, S. V.; Norman, J.; Griffith, W. P.; Marsden, S. P. Synthesis 1994, 639-666. doi:10.1055/s-1994-25538

39. Birch, A. J. J. Chem. Soc. 1944, 430-436. doi:10.1039/JR9440000430

40. Trivedi, B. K. Antihyperlipidemic and Antiatherosclerotic Compounds and Compositions. Eur. Pat. Appl. 0335375, October 4, 1989. Chem. Abstr. 1990, 112, 178376w.

\section{License and Terms}

This is an Open Access article under the terms of the Creative Commons Attribution License

(http://creativecommons.org/licenses/by/2.0), which permits unrestricted use, distribution, and reproduction in any medium, provided the original work is properly cited.

The license is subject to the Beilstein Journal of Organic Chemistry terms and conditions:

(http://www.beilstein-journals.org/bjoc)

The definitive version of this article is the electronic one which can be found at: doi:10.3762/bjoc. 4.38 